\title{
DERECHO Y REALIDAD, UNA "LÍNEA ARBITRARIA". A PROPÓSITO DE LAS PREPERSONAS DE PHILIP DICK
}

\author{
Guillermina Federik \\ Pontificia Universidad Católica Argentina, Buenos Aires, Argentina \\ Contacto: gui.federik@gmail.com
}

Recibido: 5 de noviembre de 2020

Aprobado: 4 de febrero de 2021

Para citar este artículo:

Federik, G. (2021). "Derecho y realidad, una 'línea arbitraria'. A propósito de las prepersonas de Philip Dick".

Prudentia Iuris, N. 91, pp. 157-181

DOI: https://doi.org/10.46553/prudentia.91.2021.pp.157-181

Resumen: A un año del fallo Roe vs. Wade y con la intención de demostrar sus errores, Philip Dick creó una distopía en la cual, por una ley del Congreso, los niños de hasta doce años de edad son pre-personas, por lo que pueden ser abortados. La ley, entonces, inventó una nueva categoría de seres -prepersonas- inferiores a los otros humanos -personas. Pero ¿puede una ley establecer categorías ontológicas entre los seres humanos? El Derecho, ¿puede crear o inventar la realidad? ¿Existe alguna relación entre Derecho y realidad? Estos interrogantes se responderán a medida que el autor nos descubre su concepto de realidad, de Derecho y de hombre que subyacen en toda su obra.

Palabras clave: Pre-personas, Philip Dick, Filosofía del Derecho, Aborto, Derecho y realidad. 


\title{
Law and Reality, an "Arbitrary Line". Regarding the Pre-Persons by Philip Dick
}

\begin{abstract}
Just a year after the Roe $v$. Wade case and in order to demonstrate its mistakes, Philip Dick published a dystopian story where Congress decides that 12-year-old children are "pre-persons", and therefore can be legally aborted. The law, then, created a new category of human beings -prepersons- inferior to other human beings - persons. But, can law determinate ontological categories between human beings? Can law create or shape reality? Is there any relationship between law and reality? These questions will be answered gradually as the author reveals to us his concept of reality, law and humanity that informs all of his work.
\end{abstract}

Keywords: Pre-persons, Philip Dick, Philosophy of Law, Abortion, Law and Reality.

\section{Legge e realtà, "una linea arbitraria". Per quanto riguarda i pre-persone di Philip Dick}

Sommario: Appena un anno dopo il caso Roe v. Wade e per dimostrare i suoi errori, Philip Dick ha pubblicato una storia distopica in cui il Congresso decide che i bambini di 12 anni sono "pre-persone" e quindi possono essere abortiti legalmente. La legge, quindi, ha creato una nuova categoria di esseri umani -persone- inferiore agli altri esseri umani -persone. Ma la legge può determinare categorie ontologiche tra gli esseri umani? Può la legge creare o plasmare la realtà? C'è qualche relazione tra legge e realtà? A queste domande verrà data risposta man mano che l'autore ci svela il suo concetto di realtà, diritto e umanità che informa tutto il suo lavoro.

Parole chiave: Pre-persone, Philip Dick, Filosofia del Diritto, Aborto, Legge e realtà. 
"Mirando al suelo, sin enfrentar a su madre, el muchacho dijo: -Yo no siento que ahora tenga alma. Me siento como siempre. —Es una cuestión legal —dijo decidida la mujer-”.

(Dick, 2011, “Las prepersonas”).

\section{Introducción*}

En octubre de 1974, The Magazine of Fantasy and Science Fiction publicaba "The pre-persons" ("Las prepersonas"), de Philip K. Dick (19281982), un autor que, salvo mínimas excepciones, dedicó su vida a escribir obras de ciencia-ficción. Sin embargo, este relato corto, aun conservando la esencia del autor, constituyó no sólo una excepción a su estilo, sino también la incursión en un género particular: la distopía.

Editado a tan sólo un año del famoso caso Roe vs. Wade (1973), el relato parece utilizar la distopía como una herramienta, como un medio para poder expresar las funestas consecuencias y la irracionalidad del aborto a través de la amplificación de las ideas y argumentos que rodearon al fallo.

Aun cuando este propósito, de por sí, despierta un indudable interés, Philip Dick no deja de introducir también, tal vez por la cercanía de la temática, las dos preguntas que, cual hilos conductores, atraviesan todas sus obras: ¿Qué es la realidad? ¿Qué es el hombre?.

Ahora bien, cuando el autor introduce su interrogante sobre la realidad, plantea asimismo otros: ¿existe la verdad?; al Derecho, ¿le interesa?; ¿cuál es la relación entre Derecho y verdad? Por su parte, cuando debate sobre la esencia del hombre, automáticamente, nos inserta en la cuestión jurídica central de la obra: el Derecho, ¿puede crear realidad?, ¿la puede inventar?

Así como "Las prepersonas" fue inspirado en la problemática del aborto suscitada, en gran medida, por un caso judicial, este artículo intentará analizar, desde la obra literaria, los problemas filosófico-jurídicos que plantea.

* La autora publica este trabajo en el marco del Proyecto de Investigación "Principales problemas de justicia y su solución en la literatura universal”, dirigido por el Dr. Siro M. A. De Martini. Programa Ius - Acreditación de Proyectos de Investigación Jurídica. Investigación jurídica aplicada. Facultad de Derecho. UCA. Convocatoria 2019-2021.

1 El mismo autor declaró: "No puede decir que sea una autoridad en nada, pero puede decir honestamente que determinados temas me fascinan, y que escribo sobre ellos todo el tiempo. Los dos temas básicos que me fascinan son ‘¿Qué es la realidad?’ y ‘¿Qué constituye el auténtico ser humano?'. Durante los veintisiete años en los que he publicado novelas e historias he investigado estos dos temas interrelacionados una y otra vez. Los considero temas importantes". Dick, P. K. (2018b). "Cómo construir un universo que no se derrumbe dos días después”. En Kike, G. (Trad.). Las pre-personas. Biblioteka otras puertas, 202-204 (trabajo original publicado en 1978). 
Sobre estas bases, conviene analizar, en primer lugar, el interrogante más temprano que introduce el autor en su obra, el cual será, también, el comienzo del camino que creó para responder a los restantes: ¿Qué es la realidad?

\section{Deseo y realidad}

“'Sucede de vez en cuando', escribió T. S. Eliot, 'que un poeta, por algún extraño accidente, expresa el pensamiento de su generación al mismo tiempo en que está expresando sus propias ideas que son, por el contrario, muy diferentes a las de su generación"'2. Samuel Umland introduce a Philip Dick utilizando estas palabras, lo cual es indudablemente acertado si se tiene en cuenta la historia personal del autor.

Nació el 16 de diciembre de 1928 en Chicago, Illinois, Estados Unidos y desde pequeño, debido a que su padre era Marine, se interesó por las dos grandes Guerras Mundiales, a través de las cuales tomaría contacto con la cultura alemana; en especial, con sus autores escépticos. En consecuencia, su pensamiento se verá influenciado por el "escepticismo filosófico" que fue uno de "los más profundos y duraderos efectos de la guerra fría"3.

Se ha dicho que el escepticismo filosófico suele tener una función "despertadora", "despabiladora", que llama a la argumentación ${ }^{4}$. La propuesta escéptica "[...] cuestiona radicalmente la posibilidad de una fundamentación del conocimiento, o la viabilidad de una explicación de las condiciones y principios que hacen posible el conocimiento de objetos" ${ }^{5}$. Se podría decir, entonces, que este pensamiento filosófico cuestiona la posibilidad del hom-

2 “'It happens now and then', T. S. Eliot wrote, 'that a poet by some strange accident expresses the mood of his generation, at the same time that he is expressing a mood of his own which is quite remote from that of his generation"'. La traducción de este fragmento de texto y de los próximos a utilizar -con excepción de la obra principal y de los que oportunamente se aclararán- es nuestra. Umland, S. J. (1995), "Introduction". En Umland, S. J.; Freedman, C.; Easterbrook, N.; Wessel, K.; Palmer, C.; Wolk, A.; Umland, R. A.; Rickman, G.; Abrash, M.; Jakaitis, J.; Feehan, M. Philip K. Dick: Contemporary Critical Interpretations. Connecticut. Greenwood Press, 1.

3 Así lo expone Umland Samuel, al decir: "Dick himself claimed that he inherited the left-liberal, anti-authoritarian politics of the Berkeley milieu, but he also, and perhaps most importantly, inherited the philosophical skepticism that has been one of the more profound and lasting effects of the cold war".

4 "Se le ha solido atribuir al escepticismo filosófico moderno un papel desafiador y una función despertadora, activadora de la argumentación filosófica”. Hoyos, L. E. (2001). El escepticismo y la filosofía trascendental: estudios sobre el pensamiento alemán a fines del siglo XVIII. Bogotá. Universidad Nacional de Colombia, Siglo del Hombre Editores, pp. 112-113.

5 Hoyos. Ob. cit., 115. 
bre de conocer la realidad. Una realidad que, sin embargo, estamos llamados a conocer... que experimentamos de forma inevitable.

Desde esa profunda experiencia de la realidad va a partir el autor en "Las prepersonas", a través de la utilización de múltiples imágenes sensoriales y de la empatía con uno de los sentimientos más arrolladores: el miedo.

Walter, un niño que ya cumplió los doce años, está escondido entre medio de las zarzamoras deseando ser invisible para que el camión de los abortos no lo lleve.

Vive en un país donde, según una ley del Congreso, el alma ingresa al cuerpo a los doce años -cuando se aprende a formular ecuaciones algebraicas-, por lo que hasta el décimo segundo cumpleaños, el niño es una prepersona.

Aunque parece una mera cuestión terminológica, el no ser considerado persona permite a los padres elegir si quieren a sus hijos -en cuyo caso, deben completar la Declaración Formal de Deseabilidad- o llamar al "camión de los abortos" para que lo trasladen al Servicio Comunal. Una vez allí, dentro del plazo de un mes, una familia podrá adoptarlo y si nadie lo hace, los médicos le aspiran el aire de los pulmones ${ }^{6}$.

Walter escucha la sirena del camión de los abortos con espantoso terror. Teme, primeramente, por sí mismo, pero también por cualquiera de los chicos que pudiera venir a buscar.

Aunque ya cumplió los doce años de edad que la ley establece como límite, corre a ocultarse entre las zarzamoras:

"Soy invisible", murmuró en voz baja, recitando las palabras que había aprendido en el quinto grado de la escuela, y que pertenecían a Sueño de una noche de verano.

Después de eso nadie podría verlo. Quizá era cierto, quizá la frase mágica servía en la vida real, de modo que la repitió otra vez:

"Soy invisible"7.

No es casualidad que el autor introdujera, inicialmente, Sueño de una noche de verano, de Shakespeare, dado que, en lo más profundo, las dos obras posicionan a los hombres en un mismo lugar: aquel donde el deseo y la realidad se confunden.

6 Dick, P. K. (2011). "Las prepersonas". En Gandolfo, E. E. (Dir.); Pestarini, L. (Trad.). La mente Alien. Buenos Aires. Ediciones Colihue S.R.L, 192 (trabajo original publicado en 1974).

7 Otra traducción posible es: "Soy invisible, se dijo, una línea que aprendió en una puesta teatral en quinto grado de Sueño de una noche de verano, una línea de Oberón, a quien había interpretado. Tal vez ahora fuera verdad. Puede que la magia funcione en la vida real, se dijo una y otra vez. Soy invisible". Dick, P. K. (2011). "Las prepersonas". Ob. cit., 188. Dick, P. K. (2018a). "Las prepersonas". En Quintero, G. (Trad.). Las pre-personas. Biblioteka otras puertas, 5 (trabajo original publicado en 1974). 
En efecto, Oberón -que es el Rey de las Hadas- puede con su magia obrar y modificar la realidad a su gusto. Sin embargo, cuando pretende ejercer su poder en el mundo de los humanos, establece, para sí mismo, un límite insoslayable: la verdad.

Demuestra, de este modo, que la "realidad" y la "fantasía" no pueden o, mejor dicho, no deben confundirse. Mientras que en el mundo de las hadas todo es posible, entre los hombres, la magia cumple una función instrumental, ya que busca encausarlos en lo verdadero y lo correcto.

Walter, entonces, se hace eco de esa enseñanza que deja el personaje de Oberón implícitamente y, con esto, nos introduce a la idea que Philip Dick tiene sobre la realidad.

Como surge de la frase, la realidad va más allá del deseo; no es un fenómeno interior sino exterior que, por lo tanto, no dependerá de nuestras ideas y sentimientos. Por otra parte, también permite suponer, más no sea intuitivamente, que lo importante de la realidad es lo que en ella hay de verdad; en otras palabras, la verdad está en la realidad y es la razón por la cual ni la magia ni los deseos deben modificarla.

Walter sacude sus extremidades, saliendo al encuentro de su madre, encuentro que nos colocará en el centro del conflicto.

\section{Derecho o realidad}

Llorando por el miedo que había sentido a que el camión de los abortos se lo llevase, sale caminando hacia su casa, donde se encuentra con su madre, Cynthia, que lo intenta animar diciéndole: "-Te prometí, en realidad tu papá y yo te prometimos, que nunca te enviaríamos al Servicio Comunal. Y además ya eres demasiado grande. Se llevan a niños que todavía no cumplieron los doce años"; a lo que luego añade: "-Mira, ya tienes alma. La Ley dice que a los doce años un muchacho recibe su alma. Así que no puedes ir al Servicio Comunal. ¿Ves? Estás a salvo"

Sin embargo, Walter afirma: "-Yo no siento que ahora tenga alma. Me siento como siempre". A lo que su madre contesta, decididamente: "-Es una cuestión legal. [...] Lo que te importa es que ya estás legalmente a resguardo, por mucho miedo que sientas. ¿Lo comprendes?"10. Tenía alma, ya no era una pre-persona.

8 Dick (2011). Ob. cit., 189.

9 Ibídem, 190.

10 Ibídem, 190. 
Luego de lo cual, la madre le reprocha a su hijo que eso era algo que él ya sabía y que, a estas alturas, debería dejar de tener miedo. Pero Walter no pensaba igual: "Sé que no soy diferente, se decía a sí mismo, a dos años atrás, cuando era sólo un niño. Si ahora tengo alma, como dice la ley, entonces antes también la tenía. O tal vez nadie la tenga"11.

Walter oculta este razonamiento a su madre, porque le teme, porque percibe que es una más de aquellas personas que están a favor de que exista el Servicio Comunal y, principalmente, porque entiende que su madre actúa movida por un fundamento legal más que por amor. Y, tal vez, este ocultamiento sea la causa por la cual hijo y madre parecen tener una conversación coherente y, al mismo tiempo, en planos radicalmente distintos: Cynthia habla de Derecho, de ley; Walter, de realidad.

Este diálogo es el punto de quiebre de la obra a partir del cual la historia se dividirá entre aquellos que razonan la ley bajo la luz de la realidad y aquellos que razonan la realidad bajo la luz de la ley. Por ello, conviene detener la narración para analizar, más profundamente, su significado.

Dos cuestiones parecen saltar a la vista: en primer lugar, relación entre ley y realidad y, en segundo lugar, pero íntimamente unido a lo anterior, la función de la ley.

Como habíamos visto, en la obra se plantea una distopía basada, casi exclusivamente, en la existencia de un país cuyas normas establecen que se es una "pre-persona" hasta la edad de doce años, cuando ingresa el alma al cuerpo.

Walter comprende esa ley, pero aun así, teme. Debido, principalmente, a que esa norma tiene como fundamento el ingreso del alma al cuerpo, fenómeno que nunca experimentó aun siendo mayor de doce años.

El ejercicio que hace este niño, entonces, es el de constatar en la realidad aquello que dice la norma y, al no encontrar su realización en él, al no encontrarse un alma, desconfía de no seguir siendo una "pre-persona", susceptible de ser llevada al Servicio Comunal.

Frente a esta situación -como vimos-, la madre le contesta, terminante: "Es una cuestión legal..."12. Es notable que no le brinde ninguna explicación por la cual su alma ingresó al cuerpo, como, por ejemplo, que ya puede realizar ecuaciones algebraicas ${ }^{13} \mathrm{o}$ que, por su forma inmaterial, muy difícilmente pueda haber notado que había ingresado su alma; ella simplemente hace referencia a la ley. La norma, según Cynthia, puede contestar mejor que todo lo antedicho al planteo de su hijo. Esto es así por cuanto en 
el fondo lo que le está diciendo es: si el alma ingresó o no a tu cuerpo no es una cuestión sensible, es una cuestión jurídica; es así no porque la realidad así lo demuestre sino porque la ley así lo dice.

Mientras Walter le plantea una experiencia, el no poder verificar en la realidad ningún indicio de haber dejado de ser "pre-persona", Cynthia le plantea una cuestión jurídica. Y es, exactamente, en este punto, donde el autor introduce la funcionalidad de la ley.

Es conveniente volver a sopesar un aspecto: para el niño, la realidad es fundamento de la norma hasta tal grado que, si no surge de la realidad aquello que dice, si no se verifica el hecho más allá de las palabras de la ley, esta es falsa. Entonces, por lo visto, la realidad hace a su veracidad. En síntesis, Walter no sólo reconoce la existencia de un mundo más allá de la ley, sino que, sospecha, que entre este y aquella puede no haber ninguna conexión.

Para la madre, por el contrario, la norma tiene la capacidad de poder determinar el acaecimiento o no de un fenómeno externo que, por lo tanto, ya no dependería de las leyes de la naturaleza sino del mundo jurídico. En otras palabras, la ley puede regular y modificar toda la realidad. En este momento es cuando se hace clara la función de la ley que plantea el escritor.

Por lo pronto, queda de manifiesto, mediante el pensamiento de Cynthia -que es el del común de las personas en esa sociedad-, que la ley tiene la posibilidad de ir más allá de la realidad para encausarla y regularla a su gusto.

Philip Dick mostrará con mayor claridad el poder de una ley entendida como lo hacía Cynthia, recorriendo los argumentos tanto a favor como en contra del aborto. Para llevarlo a cabo, se servirá, principalmente, de aquellos fundamentos a los cuales se refirió la Suprema Corte de Justicia de los Estados Unidos de América en el caso Roe vs. Wade, sentencia que fue su fuente de inspiración para escribir esta historia.

\section{El fallo Roe vs. Wade}

Walter quedará momentáneamente en segundo plano, mientras que Ed Gantro se presenta como el opositor al aborto, revelándose contra el sistema. Dicho lo cual, conviene resaltar, más no sea brevemente, sus hazañas.

El camión de los abortos había seguido su recorrido. Esta vez, para llevarse a un niño -Earl Fleischhacker-, una prepersona no "deseada" por sus padres. De pronto, el conductor divisó a un niño que salía corriendo, queriéndose ocultar: "El niño tenía un aspecto famélico, como muchos vagabundos, pero, por otro lado, llevaba anteojos" ${ }^{14}$. Cuando el oficial Ferris le

14 Ibídem, 197. 
preguntó si tenía su carné de deseabilidad, el niño -Tim- le contestó que no. Costaba más caro de lo que sus padres podían pagar ${ }^{15}$.

Ed Gantro, papa de Tim, espetó al ver que el oficial se lo iba a llevar por no tener su carné: “-Estas leyes de aborto posparto y las anteriores donde los nonatos no tenían derechos legales deberían ser extirpadas como un tumor. Mire adónde hemos llegado. Si se puede matar a un feto sin un proceso legal, ¿por qué no a uno que ya nació? Lo que me parece que tienen en común ambos casos es la impotencia. El organismo asesinado no tiene oportunidad, para protegerse. ¿Sabe qué? Quiero que también me lleve a mí en la parte trasera del camión con los tres niños"16.

Ferris le contesta que eso sería imposible porque las leyes del Congreso habían establecido que a partir de los doce años el alma ingresa al cuerpo y se es persona, por lo que llevarlo al Servicio Comunal sería un crimen.

“-No tengo alma - dijo el padre de Tim-, cumplí doce años y no sucedió nada. Lléveme a mí también, a menos que pueda encontrar a mi alma"17. No pudiendo Ferris hacerse cargo de tal tarea, decide comunicarse con las autoridades que autorizan el traslado de este hombre de aproximadamente treinta años.

Ed Gantro, que si bien había jurado no saber hacer operaciones algebraicas, había estudiado matemáticas en la Universidad de Stanford, desconcertará a las autoridades del lugar que, finalmente, lo liberarán a él y a los restantes niños.

Sin embargo, lo más interesante sucede dentro del camión camino al Servicio Comunal: allí podremos escuchar los verdaderos argumentos detrás de la ley.

El padre de Tim dice, más como un pensamiento en voz alta que como un deseo de iniciar una conversación: “¿Cuándo entra el alma en el cuerpo?'. Pero ¿qué tipo de pregunta racional es ésa en estos tiempos? Parece el medioevo"18. Efectivamente, en el fallo Roe vs. Wade, la Suprema Corte de Justicia de los Estados Unidos había recorrido históricamente esta pregunta en base al pensamiento de la Iglesia Católica, concluyendo que "estas

15 De esta manera, Philip Dick incorpora a las pre-personas una nueva categoría de niños: los "no deseados socialmente" en razón de ser pobres, lo cual se logra a través de poner un costo al carné de deseabilidad. En estos casos, el amor que tengan sus padres por el niño es irrelevante puesto que está supeditado al cumplimiento del requisito económico que la sociedad ha impuesto para quererlo. En suma, para conservar a su hijo no basta con desearlo, sino que el padre debe además poder pagar el "precio" que la sociedad puso a su vida. Consecuentemente, podría decirse que las pre-personas se reducen ontológicamente, existencialmente, a un costo.

16 Dick (2011). Ob. cit., 202.

17 Ibídem.

18 La letra en bastardilla pertenece al original. Dick (2011). Ob. cit., 213. 
disciplinas [filósofos, teólogos, derecho canónico] abordaban diversamente la cuestión en términos del punto en el cual el embrión o feto se 'formaba' o era reconocible como humano, o en términos de cuando una 'persona' comenzaba a existir, es decir, era infundida con un 'alma' [...]" (Roe vs. Wade, 410 U.S. 113 , p. 133$)^{19}$. De lo que concluirá, teniendo en cuenta el cambio de criterio que supuestamente hubo al respecto ${ }^{20}$, que no puede llegarse a una determinación firme de la misma. Sin embargo, Philip Dick responderá, en boca de su personaje: "La Iglesia hacía mucho que sostenía, en realidad desde sus principios, que el cigoto y el embrión en que se convertía, eran una forma de vida sagrada como cualquiera que anduviera sobre la tierra"21.

Ed Gantro seguirá pensando: "Un embrión no goza de los derechos constitucionales estadounidenses, así que se lo puede matar legalmente, a través de un médico. Pero un 'feto' era una persona con derechos, al menos lo fue durante un tiempo"22.

Lo dice, claramente, haciendo referencia al considerando de la Suprema Corte estadounidense en el que, como uno de sus argumentos principales, esgrime que si bien "el apelado y ciertos amici argumentan que el feto es una 'persona' dentro del lenguaje y el significado de la Decimocuarta Enmienda"23, el apelado no podía "[...] citar ningún caso en el cual se sostenga que un feto

19 "These disciplines variously approached the question in terms of the point at which the embryo or fetus became 'formed' or recognizably human, or in terms of when a 'person' came into being, that is, infused with a 'soul' or 'animated".

20 En efecto, la Corte Suprema dirá: "The Aristotelian theory of 'mediate animation', that held sway throughout the Middle Ages and the Renaissance in Europe, continued to be official Roman Catholic dogma until the 19th century, despite opposition to this 'ensoulment' theory from those in the Church who would recognize the existence of life from the moment of conception. The latter is now, of course, the official belief of the Catholic Church". (Roe vs. Wade, 410 U.S. 113, pp. 160-161). Sobre el tema ver Pangallo, M. (2008). "El pensamiento de Santo Tomás sobre el embrión humano". En Pontificia Academia Pro Vita (Ed.). El embrión humano en la fase de preimplantación. Madrid. BAC, 114-140.

21 Dick (2011). Ob. cit., 215.

22 Ibídem, 214.

23 La Decimocuarta Enmienda, Sección Primera, establece: "Todas las personas nacidas o naturalizadas en los Estados Unidos, y sujetas a su jurisdicción, son ciudadanos de los Estados Unidos y del Estado donde residan. Ningún Estado dictará o hará cumplir ninguna ley que limite los privilegios e inmunidades de los ciudadanos de los Estados Unidos; ningún Estado podrá privar a nadie de su vida, su libertad, o su propiedad, sin un debido proceso legal; ni podrá negar a ninguna persona que esté en su jurisdicción la igualdad en la protección de la ley". Para conocer otra posible traducción, Grau, L. (2010). Nosotros, el Pueblo de los Estados Unidos: La Constitución de los Estados Unidos y sus enmiendas 1787-1992, edición bilingüe. Madrid. Universidad Carlos III de Madrid, 185). Para ver la Decimocuarta Enmienda de los Estados Unidos en el idioma original, ir a Garcia, M. J.; Lewis C. D.; Nolan, A.; Totten, M. y Tyson, A. (Eds.). (2017). Constitution of the United States of America: Analysis, and Interpretation - Centennial Edition - Interim. Washington. U.S. Government Publishing Office, https:// www.govinfo.gov/content/pkg/GPO-CONAN-2017/pdf/GPO-CONAN-2017.pdf, 1839. 
es una persona en el sentido de la Decimocuarta Enmienda" (Roe vs. Wade, 410 U.S. 113, p. 157) ${ }^{24}$. La Corte verifica que si bien esta enmienda utiliza la palabra "persona", nunca la define y en todos los casos donde dicha norma es empleada, "solo tiene aplicación posnatalmente" (Roe vs. Wade, 410 U.S. 113, p. 157) $)^{25}$. A lo que seguirá diciendo: "Todo esto, junto con nuestra observación, supra, de que a lo largo de la mayor parte del siglo XIX las prácticas de aborto legal imperantes eran mucho más libres de lo que son hoy, nos persuade de que la palabra 'persona', tal como se utiliza en la Decimocuarta Enmienda, no incluye al nonato" (Roe Vs. Wade, 410 U.S. 113, p. 158) ${ }^{26}$.

Por supuesto que la Corte podría haber sido el primer tribunal estadounidense en abarcar con el término "persona" a los no-natos. De este modo, por vía puramente nominal, el Tribunal termina creando dos categorías de seres humanos: los ya nacidos -y, por tanto- "personas" y los aún no nacidos.

Lo cual supone una idea de lo más atractiva desde el punto de vista filosófico jurídico: el Derecho, ¿puede crear una nueva categoría de seres -como las "pre-personas"-? O, en sentido más amplio, el Derecho, ¿puede crear realidad?

El autor aborda esta cuestión a través de sus consecuencias, esto es, de forma indirecta. Sin embargo, lo hace de manera tal que, aunque colateralmente, resulta verdaderamente iluminador; máxime cuando se constata que, a medida que va planteando las consecuencias de la irracionalidad de la ley, una ley que determina -crea-realidad, empieza a esbozar una pregunta mucho más profunda: ¿qué es el hombre?

De la mano de su obra, seguiremos recorriendo los restantes argumentos y adentrándonos en este atrayente interrogante.

\section{Un hombre vive, un mundo muere. La arbitrariedad}

$\mathrm{Al}$ conductor del "camión de los abortos" -Ferris- no le fue sencillo hacer subir a Tim y a Ed Gantro. Tuvo que amenazar, demostrar su autoridad,

24 "[...] the appellee conceded on reargument that no case could be cited that holds that a fetus is a person within the meaning of the Fourteenth Amendment".

25 La Corte sostendrá: "The Constitution does not define 'person' in so many words. Section 1 of the Fourteenth Amendment contains three references to 'person'. [...] But in nearly all these instances, the use of the word is such that it has application only postnatally". (Roe vs. Wade, 410 U.S. 113, p. 157).

26 "All this, together with our observation, supra, that, throughout the major portion of the 19th century, prevailing legal abortion practices were far freer than they are today, persuades us that the word 'person', as used in the Fourteenth Amendment, does not include the unborn". 
consolar y hasta intentar disuadirlos. Para lo cual utilizó varios argumentos, muchos de ellos especialmente significativos, ya que fueron ideas que rodearon la polémica del aborto durante la época en que Philip Dick escribió esta historia.

“-Como se están agotando la energía y los combustibles [...] se hace necesario que la población decrezca radicalmente. O dentro de diez años ya no habrá alimentos para nadie”; a lo que añadió: “-iY cuál es la diferencia entre un feto de cinco meses y lo que aquí tenemos? [Haciendo referencia a los niños dentro del camión] —continuó diciendo Ferris-. En ambos casos tenemos un niño no deseado" 27 .

Esta imagen del mundo que se expresa a través del personaje sugiere una mirada pesimista, una imagen exterior de agotamiento e insuficiencia, de un mundo que se apaga, rápidamente, vorazmente. La naturaleza usualmente se presenta con la idea de fecundidad, es madre... sin embargo, el conductor no habla, ni siquiera, de un mundo que crece de forma insuficiente sino de un planeta que muere. Lo cual coloca al hombre en una situación angustiante: el entorno que lo envuelve está en peligro y lo pone en riesgo de matarlo, en este caso, de hambre. Cuantas más son las personas, menos bienes poseen cada uno, hasta que no haya "alimentos para nadie". Cuando él contempla su realidad no hay orden ni armonía, no es un mundo que alienta a la vida. Es entendible, en ese entorno, que se sienta llamado a intervenir radicalmente. Sin embargo, la inspiración de sus decisiones no será en un ambiente fructífero, feliz, generoso, sino, por el contrario, un ambiente desalentador, proclive a la muerte ${ }^{28}$.

Empero, introduce una idea llamativa, sobre la que, más tarde, Ed Gantro formulará sus posiciones: ¿qué diferencia hay entre una "pre-persona” y una persona?, que llega hasta el punto de cuestionar ¿qué diferencia hay entre las mismas "pre-personas"? ¿Por qué algunas pueden gozar de una familia y otras deben ser "eliminadas"? Al parecer, porque así lo desean sus padres. El autor sugiere, de esta forma, una noción de deseo que trasciende la esfera privada y se vuelve medida, criterio de justicia, para decidir sobre la vida o muerte de otros.

No es una cuestión menor advertir que si un niño es amado por sus padres, entonces más allá de la falta de alimentos o de la necesidad de un decrecimiento poblacional, el mundo le tendrá que hacer un lugar. La vida o la muerte es una cuestión de amor, pero un amor entendido como deseo, lo cual no es, ciertamente, lo mismo.

27 Dick (2011). Ob. cit., 201.

28 Esta visión del planeta puede relacionarse con el "informe Kissinger" (National Security Council, 1974). 
“—¿Usted está de acuerdo con estas leyes? —dijo el padre de Tim, levantando la mirada hacia él.

-Bien, eso lo decidieron en Washington y lo que hagan tendrá que resolver nuestras necesidades en estos días de crisis - dijo Ferris-. Yo sólo hago cumplir los edictos. Si la Ley cambiara... bien, tendré que llevar cartones de leche vacíos para que los reciclen y todos seríamos igual de felices"29.

Resuenan las palabras de Cynthia: es una cuestión legal. Pero en la última frase del conductor del "camión de los abortos", parece esconderse una consecuencia de esta ley creadora de realidad: según lo que se decidió, lo que dice la norma, un niño hasta los doce años de edad es una "pre-persona" que, si no tiene su carné de "deseabilidad", puede ser llevado al Servicio Comunal, pero si mañana cambia la ley, "tendré que llevar cartones de leche vacíos para que los reciclen y todos seríamos igual de felices"30.

No hay un límite más allá de la norma, una razón inamovible por la cual la ley debe ser como es y no de otra manera. Todo depende de una decisión legislativa, fundada, por lo visto, en el deseo de los padres y en la conveniencia de reducir la población mundial por la escasez de recursos.

No se busca llegar a la verdad, a un principio absoluto, inconmovible, sobre el cual fundar una ley. No sólo no parece existir, ni siquiera se busca. Los fundamentos son la necesidad -que más bien se presenta como una exageración de un miedo a tener menos que a no tener-y el deseo. Razones egoístas que surgen del interior del hombre y que se intentan llevar hasta su realización exterior, veremos, luego, a pesar de sus tristes consecuencias. Son una fuerza interior ilimitada, no sujeta a ningún valladar, sumado a una mirada de la realidad acotada, egoísta, disvaliosa, las razones por las cuales se legisló aquella ley que él tanto defiende y que, si mañana cambiara, tanto así dejaría de defender.

Una vez que todos estuvieron arriba del camión de los abortos, Ferris siguió meditando estas ideas en su cabeza, hasta llegar a una conclusión razonable -dados los presupuestos de los cuales parte- pero, también, sorprendentemente honda: "Cuatro conejos locos saltando en el camino [...]. La gente contamina el medio ambiente natural. ¿Cómo sería esta parte del país antes de que llegara el hombre? Bien, pensó, con el aborto posparto teniendo lugar en cada condado de los Estados Unidos podremos ver nuevamente ese día. Podremos ponernos de pie y una vez más ver una tierra virgen.

Nosotros, pensó. Pero sospecho que no habrá un nosotros. Grandes computadoras inteligentes [...] van a examinar el paisaje con sus microcámaras y lo encontrarán muy placentero.

29 Dick (2011). Ob. cit., 201.

30 Ibídem. 
Ese pensamiento no le levantó el ánimo"31.

Quería una tierra nueva para un "nosotros" futuro, pero al parecer, no para uno humano. El aborto iba a traer un mundo con bienes suficientes, de los cuales se serviría una población "robótica" que, seguramente, no los necesita.

El escritor sugiere ideas de la ciencia ficción, su género predilecto, y al hacerlo invita a una pregunta: un mundo mejor, pero ¿para quién? Ferris hubiera querido que fuera para los hombres, pero lo duda porque las ideas que se utilizan para llevarlo a cabo suponen la aniquilación de esos deseados habitantes futuros. Un nuevo mundo para el hombre del mañana, un hombre quizás inexistente, o sin corazón, como una máquina.

Aquí yace el primer fundamento humano de las ideas de nuestro autor: la felicidad del hombre debe orientar el fin de todas nuestras acciones. No se habla de una humanidad futura, abstracta, lejana y hueca. Debemos construir un mundo para un hombre ¡vivo!

Todo lo dicho cobrará especial sentido cuando veamos las reflexiones de Ed Gantro. Sin embargo, primero debemos dialogar con Cynthia.

\section{Los límites de la injusticia: la humanidad}

Cynthia se presenta no sólo como un personaje paradigmático dentro de la historia sino, veremos luego, como la encarnación de la sociedad y de todas las personas pro-aborto; en especial, las madres. Desde esta perspectiva, se pueden apreciar todos los atributos e ideas que el autor le hace hacer, decir, pensar y obrar. Conviene, entonces, ir desenvolviéndolos lentamente.

Ella le dice a su esposo que quiere tener un aborto: “_[...] para mujeres en los primeros meses del embarazo, sólo cuesta cien dólares [...] ¡El precio de diez litros de nafta! Y uno puede hablar durante horas de ello con prácticamente todo el mundo con el que se cruce" 32 .

Ian Best, el papá de Walter, la escucha atentamente y habiéndose enterado de toda su idea -la cual incluía conservar el embrión en un frasco de color- responde: “- ¿No sabes que hay gente que quiere tener un niño? ¿Incluso un torpe niño ordinario? [...]"33.

"-Es un fastidio - dijo Cynthia-. Por ejemplo, hoy llegó Walter asustado porque había visto pasar el camión del aborto. Es un fastidio tener que hacerse cargo de él. Para ti es fácil, porque estás trabajando todo el día. Pero yo $[\ldots]$ ".. 34 .

31 Ibídem, 204.

32 Ibídem, 205.

33 Ibídem, 206.

34 Ibídem. 
El escritor nos introduce, primeramente, al personaje: una mujer casada, con un niño a su cuidado todo el día. Pero inmediatamente, resalta dos aspectos de ella que formarán su individualidad.

Primeramente, y de una forma muy violenta, ella se introduce en la historia sosteniendo e incentivando las ideas de "prácticamente todo el mundo", lo cual nos lleva a la conclusión de que sus estructuras de pensamiento son, en realidad, las del promedio de la gente. Desde esta perspectiva, parece como si el autor la hubiese camuflado con el resto del mundo, como una más; sin embargo, inmediatamente le dará una singularidad muy marcada.

Sin introducirnos en el poco ejercicio de la paternidad que le reprocha a Ian o en la falta de compasión que tiene por su hijo, Cynthia mostrará en la contestación al papá de Walter una marcada tendencia egoísta, poniéndose primera en todas las circunstancias: no mira el sufrimiento de su hijo, ni valora el esfuerzo de su esposo; simplemente y únicamente, habla de ella.

La conclusión se volverá a verificar en una pintoresca situación posterior, cuando Ian Best habla con su hijo de escaparse a otro país y Cynthia lo escucha.

“-¿Otra vez tienes la fantasía de huir? - dijo Cynthia, contemplándolo.

—Los dos -interrumpió Walter-. Papá me llevará con él.

- ¿A dónde? - dijo Cynthia.

-A cualquier lugar donde nos puedan llevar las vías del Amtrak —dijo Ian.

—iY qué [...] se supone que voy a hacer yo cuando se hayan ido? [...] ¿Cómo me las arreglaré con las cuentas [...]?”35.

No pasa inadvertido el rechazo que Ian Best siente por su esposa pero, contemplando sus próximas palabras, se advierte que no la odia a ella como persona sino como representación de los restantes dos aspectos del personaje delineados por Philip Dick.

Cynthia también encarna a la sociedad toda, pero no de cualquier manera, sino que el autor, haciendo uso de sus habilidades en la ciencia ficción -en lo que suele incurrir cuando quiere introducir un pensamiento personal-, nos traerá una divertida y exagerada representación de la sociedad como un monstruo.

“-Podrías venir con nosotros — dijo Ian [a su esposa] — y atrapar peces zambulléndote en la Bahía Inglesa, y luego los destrozarías con tus agudos dientes. Podrías reducir la población de peces de la Columbia Británica en una noche. Todos esos peces preguntándose vagamente qué estaba pasando [...] nadaban tranquilamente y de pronto [...] aparece el ogro, el monstruo 
destructor de peces con un único ojo luminoso en el centro de la frente, que cae sobre ellos y los hace pedazos. [...]

-Pero papá - dijo Walter-, supongamos que no sobrevive ningún pez.

—Entonces todo habrá sido en vano - dijo Ian-, excepto para el placer personal de tu madre que habría eliminado especies enteras en la Columbia Británica, donde la pesca es la industria más importante, y muchas otras especies dependían de esta industria para sobrevivir.

-Pero entonces nadie en la Columbia Británica tendría trabajo — dijo Walter.

—No - dijo Ian-, rellenarán latas con peces muertos y se las venderán a los estadounidenses. Mira, Walter, en los viejos días, antes de que tu madre matara a mordiscones a todos los peces de la Columbia Británica, los lugareños simples se quedaban quietos junto al río con un palo en la mano, y cuando pasaba un pez se lo clavaban en la cabeza. Todo esto creará trabajo, no lo eliminará"36.

Es un relato sumamente curioso y, asimismo, claro. Ya no se trata solamente de Cynthia, es evidente que una sola persona no podría "devorar todos los peces de la Columbia Británica”. El ogro con "un único ojo luminoso en el centro de la frente" parece hacer reminiscencia a esa lámpara frontal que utilizan los médicos para las cirugías que, en el caso del aborto, consiste -literalmente- en desmembrar a la criatura. Es un detalle importante el hecho de que ya no se refiere a "aspirarles el aire de los pulmones" como en el cuento, sino a lo que sucede en la realidad.

Sigue exponiendo un pensamiento muy parecido al que tiene Ferris al final: si sigue siendo así, especies enteras morirían; con la terrible consecuencia, en principio ficticia pero que podría ser real, de afectar otras especies que vivían de estas. Pero a la vez, la industria no se frenaría, se exportaría y habría más trabajo que antes. Este es, seguramente, el punto más interesante de la micro-historia: antes se pescaba, pero rústicamente, limitadamente.

De lo dicho se desprenden, al menos, dos líneas interpretativas posibles. En una lectura continuada podríamos decir que hace referencia a esos abortos realizados fuera de la ley cuando esta es prohibitiva y que, a comparación de lo que sucede cuando es legal, supone un menor número de casos o una intervención más clandestina, rústica. Pero también se podría pensar que en esta conclusión hace un giro radical y, dejando de utilizar la pesca

36 La letra en bastardilla pertenece al original. En cuanto a la frase "todo esto creará trabajo, no lo eliminará", podría inferirse de la misma una alusión a las ganancias que genera la industria del aborto -legal o ilegal-y que no se limita a las transacciones sobre medicamentos o asistencia profesional, sino al negocio publicitario o clínicas privadas, etc. Dick (2011). Ob. cit., 209-210. 
como sinónimo de práctica abortiva, cuenta cómo la misma naturaleza es la que elige, de forma simple y singular, uno a uno, caso por caso, qué embrión nacerá o no, qué pez saldrá del agua; esta imagen deja un cierto aroma, más no sea rudimentariamente, a un orden natural.

Aunque el tercer aspecto que el autor dibuja en Cynthia no ocupa un lugar primordial en su relato en cuanto a la extensión que le dedica, sí lo ocupa en cuanto a la importancia; hasta tal punto, que sólo a partir de esta perspectiva podemos conocer el corazón de Ian Best.

"-Escúchame, Walt, te voy a decir algo. - Bebió un largo sorbo de escocés y leche-. Eso se llama asesinato. [...] Hay un tipo de mujeres que defienden todo esto" 37 . Un rato más tarde, después de que la bebida ya le hubiera haya hecho efecto, piensa: “¿Dónde han ido a parar las virtudes maternas? [...]. Cuando las madres específicamente defendían a los más pequeños, débiles e indefensos"38.

Pero esos niños no son los únicos afectados ya que él mismo se siente impotente de poder defenderse, incapaz de poder escapar de lo que, como vimos, es en su mente un "monstruo".

Irse a otro país se presenta como algo idílico, pero sólo es un sueño, probablemente irrealizable. De alguna manera, se siente atado a quedarse; es como un ser paralizado de miedo que ve una escena de terror frente a sus ojos pero su cuerpo no se aleja de allí. Desde esa perspectiva, es claro que, aunque hubiera tomado un camino hacia el lugar más opuesto del universo, de nada hubiera servido... no era cuestión de alejar su cuerpo sino su corazón.

Su mujer era, ante todo, una madre que había perdido aquello que le es más natural a una madre: amar a la criatura que tomó parte de su carne y que se alimentó con la bebida más cercana, verdaderamente, al corazón.

Philip Dick golpea duramente sobre este aspecto maternal, tal vez, si seguimos su lógica, porque si una madre renuncia a su propio hijo, poco queda por esperar. En efecto, "[...] si una madre es capaz de destruir a su propio hijo [...] ya no queda ningún impedimento" (Madre Teresa de Calcuta) ${ }^{39}$.

La conversación con Cynthia aparece en la obra como el cuadro final de una escena de teatro, donde cada personaje resume su papel con el último gesto: el niño atormentado y afligido, la madre desapegada de todo vínculo maternal e Ian Best, mientras tanto, con una copa en la mano, refleja en su

37 La letra en bastardilla pertenece al original. Dick (2011). Ob. cit., 207.

38 La letra en bastardilla pertenece al original. Dick (2011). Ob. cit., 211-212.

39 La frase completa es: "El aborto mata la paz del mundo [...] Es el peor enemigo de la paz, porque si una madre es capaz de destruir a su propio hijo, ¿qué me impide matarte? ¿Qué te impide matarme? Ya no queda ningún impedimento" (Madre Teresa de Calcuta, como se citó en Notivida). 
rostro la pesadumbre de aquella lucha interna de su alma, con unos ojos a punto de llorar ${ }^{40}$.

Así es como el autor deja caer el telón de esta escena familiar, corta, pero intensísima. Sin embargo, todavía queda un diálogo más que analizar dentro de ella: el que Walter tiene con su padre. Un diálogo que esconde una nueva visión antropológica.

"Mientras se preparaba el trago llegó su hijo Walter. Su cara mostraba una palidez antinatural.

—El camión del aborto anduvo hoy por aquí, ¿no? — dijo Ian.

-Pensé que tal vez...

-De ninguna manera. Aunque tu madre y yo fuéramos a ver a un abogado y firmáramos un documento legal que suprimiera tu tarjeta $\mathrm{D}$, ya eres demasiado grande. Puedes quedarte tranquilo.

—Racionalmente ya lo sé — dijo Walter- pero...

-'No quieras saber por quién doblan las campanas, lo hacen por ti' citó incorrectamente Ian-"41.

Como un acto espontáneo, el padre adivina con facilidad qué esconde el hijo en su alma y lo hace dándole palabras al sentimiento que lo atraviesa, palabras que surgen de un poema de John Donne:

"¿Quién no echa una mirada al sol cuando atardece?

¿Quién quita sus ojos del cometa cuando estalla?

¿Quién no oye una campana cuando por algún hecho tañe?

¿Quién puede evadir esa campana cuya música lo traslada fuera de este mundo?

Ningún hombre es una isla entera por sí mismo.

Cada hombre es una pieza del continente, una parte del todo.

Si el mar se lleva una porción de tierra, toda Europa queda disminuida, como si fuera un promontorio, o la casa de uno de tus amigos, o la tuya propia.

Ninguna persona es una isla; la muerte de cualquiera me afecta,

porque me encuentro unido a toda la humanidad;

por eso, nunca preguntes por quién doblan las campanas; doblan por ti"42.

40 Dick (2018a). Ob. cit., 30-31.

41 Dick (2011). Ob. cit., 206-207.

42 "Who casts not up his eye to the sun when it rises? But who takes off his eye from a comet, when that breaks out? who bends not his ear to any bell, which upon any occasion rings? But who can remove it from that bell, which is passing a piece of himself out of this world? No man is an island, entire of itself; every man is a piece of the continent, a part of the main; if a clod be washed away by the sea, Europe is the less, as well as if a promontory were, as well as if a manor of thy friend's or of thine own were; any man's death diminishes me, because I 
Philip Dick coloca en Walter toda su predilección, coloca en este niño sólo las ideas que él cree correctas y las críticas a la ley más sabias y sencillas. Todo lo cual no es de extrañar, por otra parte, ya que el mismo escritor asegura que "hay algo enormemente poderoso en la capacidad de un niño para resistirse a lo fraudulento. Un niño tiene la visión más clara, la mano más firme" 43 . Es razonable, por lo tanto, que sea en referencia a él que se utilice este poema bellísimamente humano.

Conviene sopesarlo detenidamente: "Si el mar se lleva una porción de tierra, toda Europa queda disminuida", ese hecho lejano, de alguna manera común -como el movimiento de la marea-, me afecta terriblemente. Pero no se trata de un sentimiento pasajero, superficial, no es la consecuencia lógica de una convivencia, ni siquiera es -paradigmáticamente- el sonido de una campana, externo, aturdidor, inevitable. Sino, lo opuesto: la muerte de alguien es mi propia muerte, ya que ellas "doblan por mí".

Sea en algo material, sea en la propia existencia, nos encontramos unidos con lazos estrechísimos a todos, incluso a esos que nos parecen tan lejanos. Aunque a Walter, claro, no le parecen para nada lejanos. Porque el experimentar la suerte del otro como propia presupone apropiarse del otro. Un apropiarse que no implica coartarle la libertad, vigilarlo, rodearlo, sino unirse con el otro, estar en comunión.

Otra vez descubrimos una imagen del hombre que, en esta oportunidad, se reviste de un amor que devela en todos un amigo entrañable, que se traduce en servicio, en búsqueda, en acogida, en trato con el hermano ${ }^{44}$.

Philip Dick va construyendo un paradigma del hombre, y con el personaje de Ed Gantro nos invitará a contemplar su más elevada visión.

\section{Una ley para un hombre eterno}

El recorrido al Servicio Comunal nos introduce en la mente de Ed Gantro, inteligente y valiente, pero por sobre todo, un hombre que ama inmensamente a su hijo. Su enojo y sus miedos se sopesan y diluyen en la necesidad de Tim de que permanezca templado; siempre está atento a esos niños que viajan con él y que, a su temprana edad, enfrentan un destino trágico.

am involved in mankind, and therefore never send to know for whom the bell tolls; it tolls for thee". Donne, J. John Donne Devotions. Christian Classics Ethereal Library, 130. Recuperado de https://www.ccel.org/ccel/d/donne/devotions/cache/devotions.pdf.

43 Dick (2018b). Ob. cit., 230.

44 Arribas Sánchez, P. (2003). Evangelio de una Santa. Buenos Aires. Grupo Editorial Lumen. 
En el marco de esa relación tan unida que surge en la cabina del camión, nos encontramos con la última visión antropológica:

"[Ed Gantro] Levantó la vista hacia los tres niños asustados e intentó pensar en algo que decirles... no sólo a su propio hijo, sino a los tres.

- 'Mira' — dijo, citando-, 'te diré un secreto sagrado. No todos dormimos en la muerte. Nosotros...' - Pero no pudo recordar el resto. Torpe, pensó desanimado-. 'Nosotros despertaremos' — continuó, haciéndolo lo mejor que podía- . 'En un relampagueo. En el parpadeo de un ojo" 45 .

Cuando levantó la vista, se encontró con tres personas que, a una edad aún muy tierna, se enfrentaban a la muerte; entonces, intentó consolarlos con un pasaje del Nuevo Testamento.

"Les voy a revelar un misterio: No todos vamos a morir, pero todos seremos transformados. En un instante, en un abrir y cerrar de ojos, cuando suene la trompeta final -porque esto sucederá- los muertos resucitarán incorruptibles y nosotros seremos transformados" 46 .

Cabría analizar varios detalles de la frase como, por ejemplo, la razón por la cual utilizó esta cita o las ideas religiosas del autor, pero sería casi corromper su sentido porque, en tan sólo un párrafo, está comprendido un abismo: el hombre como un ser llamado a la trascendencia.

Ferris impone la necesidad de un hombre verdaderamente vivo y Ed Gantro la de un hombre vivo para siempre. La muerte es tan solo una transformación, un paso de lo corruptible a lo incorruptible y la vida se transforma en una promesa de ser experimentada en plenitud.

En poco tiempo más, se llega al final de la obra: cuando todos son liberados debido a que las autoridades temen que todo sea un engaño de Ed Gantro para la prensa y quedar como asesinos, con la temible consecuencia de un recorte presupuestario. Así, vuelven a sus casas, deseando escapar de ese país pero sabiendo finalmente que nunca lo van a hacer.

\section{Derecho y realidad. Conclusiones}

En las escasas páginas de esta obra, Philip Dick logra que el lector vivencie el absurdo de una sociedad que ha legalizado el aborto. La edad o la capacidad de realizar ecuaciones algebraicas que se establecen como parámetros son solo cuestiones secundarias. Su único fin es ilustrar las con-

45 Dick (2011). Ob. cit., 215-216.

46 Levoratti, A. J. y Trusso, A. B. (Trads.). (1986). El libro de la Nueva Alianza. Argentina. Fundación Palabra de Vida. 1 Corintios 15: 51-52. 
secuencias de la "línea arbitraria" que trazaron, lo irracional de los fundamentos por los cuales se lo legalizó.

Ed Gantro lo dirá con suma claridad: “[...] el error principal de los que apoyaron los abortos desde un principio, se dijo, fue la línea arbitraria que trazaron. Un embrión no goza de los derechos constitucionales estadounidenses, así que se lo puede matar legalmente, a través de un médico. [...] Pero aun así, ¿dónde se podía trazar la línea? ¿Cuando el bebé realizaba su primera sonrisa? ¿Cuando decía la primera palabra? ¿O cuando tomaba por primera vez un juguete para jugar? [...]"47.

Como fue señalado en un comienzo, "Las prepersonas" surge como crítica al fallo Roe vs. Wade, mediante el cual se les niega a los nonatos la protección del Derecho porque, y este es el corazón del conflicto, se desconoce que son personas.

En efecto, la Corte Suprema de los Estados Unidos crea jurisprudencialmente dos categorías de seres humanos: los nacidos, que son personas amparadas por la Decimocuarta Enmienda, y los no nacidos, quienes tienen un derecho a la vida relativo ya que cede frente al deseo -no deseo- de que vivan de sus padres (en rigor, en el fallo, solamente de su madre).

La cuestión que surge, entonces, es qué son -entitativamente hablando- los nonatos. Sería razonable suponer que no se los ha querido asimilar a las cosas, o a los animales, o a las plantas. Se trataría de otra categoría de seres, "algo" inmediatamente anterior a una persona, una pre-persona ${ }^{48}$.

Que la Decimocuarta Enmienda no incluya expresamente a los bebés no nacidos dentro del vocablo "persona" y que la historia jurisprudencial estadounidense también lo omita, no son argumentos que acarreen inevitablemente la negación de su carácter. Esto así por cuanto nada imposibilitaba que el Tribunal fuera el primero en abarcar con el término "persona" a los nonatos. Máxime si se tiene en cuenta que más allá de cuál significación jurídica se le otorgue al término "persona", no cabe duda que se refiere a "seres humanos" y que dicha cualidad no se ve modificada por el nacimiento.

47 La letra en bastardilla pertenece al original. Dick (2011). Ob. cit., 214.

48 Similar razonamiento se ha aplicado en un comentario al proyecto de "Ley de protección de embriones no implantados" (Proyecto de Ley, Expediente 1541-D-2019), con los siguientes términos: "Ahora, si el embrión humano no es un ser humano, ¿qué es?, ¿a qué categoría de entes pertenece? Ni los legisladores, ni los juristas, ni los jueces, han pretendido categorizar a los embriones humanos como cosas o como vegetales o como animales. Parecería más bien que nos encontramos frente a un nuevo tipo de seres (presumiblemente vivos) creados por el Derecho. Pero ¿es esto lógica, ontológica o jurídicamente posible, quiero decir, verdaderamente posible? De Martini, S. M. A. (2019). "La realidad como fundamento del Derecho". Academia Nacional de Derecho y Ciencias Sociales de Buenos Aires. Anales Nro. 57, 4. 
"En realidad [...] es sólo un pretexto [...] un pretexto para cazar a los desvalidos" 49 , sintetiza Ed Gantro.

De alguna manera, Roe vs. Wade es una demostración del absurdo de un derecho que pretende suplantar la realidad por una construcción artificial para justificar un propósito: legalizar el deseo de ciertas mujeres a terminar con la vida del niño concebido en su seno.

El centro de validez de la decisión de la Corte es, por tanto, el deseo. En efecto, el aborto es, por sobre todo, algo socialmente querido. El consenso en su "deseabilidad", entonces, se convierte en el justificativo de su existencia como derecho.

En este contexto, el personaje de Cynthia, que -de algún modo- representa a la sociedad toda, nos permite acercarnos de forma más precisa a sus características: la frivolidad, el egoísmo y la despreocupación por las consecuencias que conlleva materializar sus anhelos.

Ahora bien, sería conveniente detenernos en este último punto ya que por este afán de "materializar" los deseos el Derecho se convertirá en un Derecho "creador".

"[...] desear algo no hace que eso se convierta en realidad"50, dirá sensatamente Walter. Sin embargo, a pesar de no tener la magia de Oberón, el hombre parece haber encontrado en la ley la manera de hacerlo.

Lo que lleva a preguntarnos si el Derecho puede prescindir de la realidad y obrar con completa libertad o si, por el contrario, la realidad lo limita. En resumen, el Derecho, ¿crea realidad o crea, a lo sumo, ficciones que conviven con una realidad existente más allá de lo que los hombres prescriban?51

Cuando Walter dice que "desear algo no hace que eso se convierta en realidad", lo que está queriendo hacer es advertir que un deseo no deja de ser un deseo, aunque esté estipulado por la ley. Que el Derecho no puede modificar la naturaleza de las cosas, sino que estas tienen una realidad que trasciende al mismo hombre. Que lo injusto no deja de ser injusto, aunque haya una ley que lo permita.

En efecto, la verdad y lo real es un límite para el Derecho. Un límite que se puede cruzar porque es invisible, pero no por eso menos existente y real.

Philip Dick no se contentará con mostrar la arbitrariedad del aborto, sino que intentará también ilustrar las consecuencias de pasar esa "invisi-

49 Dick (2011). Ob. cit., 213.

50 Ibídem, 189.

51 Siro M. A. De Martini. Ob. cit., 11, ha llamado la atención sobre el intento jurídico de "construir una nueva realidad. Una suerte de realidad paralela, onírica, ideológica". 
ble medida"52. Nos despertará del "sueño", de ese estado de inconciencia en el que vivimos.

No nos debería asombrar que la consecuencia de infringir aquellas leyes que gobiernan la realidad sea la de quebrantarnos a nosotros mismos. "Las prepersonas" hace un insistente llamado a nuestra humanidad; esto es, a la tierna unión entre los hombres que se reconocen, ante todo, como hermanos.

Este es el camino que nos señala el autor para poder regresar a la "conciencia”, que en este caso no es más que el reconocimiento de la existencia del prójimo, un bebé en sus primeros instantes de vida.

Insisto, no nos debería asombrar que la solución a un mundo donde reina el egoísmo, sea el llamado a la humanidad. Porque el verdadero hombre no se realiza completamente sino cuando ama, y el amor consiste en reafirmar al otro en su existencia ${ }^{53}$.

El amor hace que digamos "soy hombre, a ningún otro hombre estimo extraño" 54 , el amor logra que no nos preguntemos por quién doblan las campanas, porque sabe que siempre doblan por nosotros ${ }^{55}$.

\section{Bibliografía}

Arribas Sánchez, P. (2003). Evangelio de una Santa. Buenos Aires. Grupo Editorial Lumen.

Arteaga Botello, N. (2018). "La historia como realidad y ficción: los distintos mundos de El hombre en el castillo". Revista Académica Del CISAN-UNAM, Vol. 13, Nro. 2, 299-318.

Arteaga Botello, N. (2018). "La vigilancia en la obra de Philip K. Dick: Identidades, deseos y conflictos sociales". Valenciana, Nro. 21, 153-186.

Broderick, D. (2003). "New Wave and backwash: 1960-1980". En James, E.; Mendlesohn, F. (Eds.). The Cambridge companion to Science Fiction. New York. Cambridge University Press, 48-63.

Csicsery-Ronay, I. Jr. (2003). "Marxist theory and science fiction". En James, E.; Mendlesohn F. (Eds.). The Cambridge companion to Science Fiction. New York. Cambridge University Press, 113-124.

52 En referencia a la famosa frase de Solón: "Pero lo más difícil es llegar a la percepción inteligente de la invisible medida, al hecho de que todas las cosas llevan consigo límites". Jaeger, W. (2001). Paideia, los ideales de la cultura griega. Fondo de Cultura Económica México, 138.

53 Pieper, J. (2010). Las virtudes fundamentales. Trinidad y Tobago. Morgan Editores, $422-431$

54 Unamuno, M. D. (1970). Del sentimiento trágico de la vida. Madrid. Aguilar, 729.

55 Donne. Ob. cit., 130. 
De Martini, S. M. A. (2019). "La realidad como fundamento del Derecho". Academia Nacional de Derecho y Ciencias Sociales de Buenos Aires. Anales Nro. 57.

Dick, P. K. (2011). "Las prepersonas". En Gandolfo, E. E. (Dir.); Pestarini, L. (Trad.). La mente Alien. Buenos Aires. Ediciones Colihue S.R.L, 188-224 (trabajo original publicado en 1974).

Dick, P. K. (2018a). "Las prepersonas". En Quintero, G. (Trad.). Las pre-personas. Biblioteka otras puertas, 5-43 (trabajo original publicado en 1974).

Dick, P. K. (2018b). "Cómo construir un universo que no se derrumbe dos días después”. En Kike, G. (Trad.). Las pre-personas. Biblioteka otras puertas, 202-231 (trabajo original publicado en 1978).

Donne, J. John Donne Devotions. Christian Classics Ethereal Library. Recuperado de https://www.ccel.org/ccel/d/donne/devotions/cache/devotions.pdf.

Duncan, A. (2003). “Alternate history”. En James, E.; Mendlesohn F. (Eds.). The Cambridge companion to Science Fiction. New York. Cambridge University Press, 209-218.

Garcia, M. J.; Lewis C. D.; Nolan, A.; Totten, M. y Tyson, A. (Eds.). (2017). Constitution of the United States of America: Analysis, and Interpretation - Centennial Edition - Interim. Washington. U.S. Government Publishing Office, https://www. govinfo.gov/content/pkg/GPO-CONAN-2017/pdf/GPO-CONAN-2017.pdf.

Grau, L. (2010). Nosotros, el Pueblo de los Estados Unidos: La Constitución de los Estados Unidos y sus enmiendas 1787-1992, edición bilingüe. Madrid. Universidad Carlos III de Madrid.

Gresham, M. G. (2016). VALIS: An Introductory Guide [Senior Seminar Paper, Ferrum College], https://www.ferrum.edu/wp-content/uploads/2019/11/Gresham_ Valis-An-Introductory-Guide.pdf.

Gwyneth, J. (2003). “The icons of science fiction”. En James, E.; Mendlesohn, F. (Eds.). The Cambridge companion to Science Fiction. New York. Cambridge University Press, 163-173.

Hoyos, L. E. (2001). El escepticismo y la filosofía trascendental: estudios sobre el pensamiento alemán a fines del siglo XVIII. Bogotá. Universidad Nacional de Colombia, Siglo del Hombre Editores.

Jaeger, W. (2001). Paideia, los ideales de la cultura griega. Fondo de Cultura Económica México.

James, E. (2003). “Utopias and anti-utopias”. En James, E.; Mendlesohn, F. (Eds.). The Cambridge companion to Science Fiction. New York. Cambridge University Press, 219-229.

Levoratti, A. J. y Trusso, A. B. (Trads.). (1986). El libro de la Nueva Alianza. Argentina. Fundación Palabra de Vida.

Madre Teresa de Calcuta, como se citó en Notivida. Aborto, citas de la Madre Teresa de Calcuta, http://www.notivida.org/Articulos/Aborto/Aborto,\%20Madre\%20 Teresa.html.

National Security Council. (1974) National Security Study Memorandum, NSSM 200 [The Kissinger report]. Recuperado de https://pdf.usaid.gov/pdf_docs/PCAAB500.pdf. 
Pangallo, M. (2008). "El pensamiento de Santo Tomás sobre el embrión humano". En Pontificia Academia Pro Vita (Ed.). El embrión humano en la fase de preimplantación. Madrid. BAC, 114-140.

Pieper, J. (2010). Las virtudes fundamentales. Trinidad y Tobago. Morgan Editores.

Proyecto de Ley, Expediente 1541-D-2019. Protección de Embriones no Implantados -Régimen. 5 de abril de 2019, https://www.diputados.gov.ar/proyectos/proyecto. jsp?exp=1541-D-2019.

Ramírez, J. (2015). "From Anti-Abundance to Anti-Anti-Abundance: Scarcity, Abundance, and Utopia in Two Science Fiction Writers". RCC Perspectives, 2, 83-90. Recuperado de http://www.jstor.org/stable/26241320.

Reyes, A.; Romero, F.; De Onís, F.; Baeza, R. y Arciniegas, G. (Dirs.). (1952). Poetas Líricos Ingleses (Vol. XXXIV). Buenos Aires. W. M. Jackson INC.

Roe vs. Wade, 410 U.S. 113 (Corte Suprema de EE.UU. 1973). Recuperado de https://tile.loc.gov/storage-services/service/ll/usrep/usrep410/usrep410113/usrep410113.pdf.

Umland, S. J. (1995), “Introduction”. En Umland, S. J.; Freedman, C.; Easterbrook, N.; Wessel, K.; Palmer, C.; Wolk, A.; Umland, R. A.; Rickman, G.; Abrash, M.; Jakaitis, J.; Feehan, M. Philip K. Dick: Contemporary Critical Interpretations. Connecticut. Greenwood Press, 1-6.

Unamuno, M. D. (1970). Del sentimiento trágico de la vida. Madrid. Aguilar. 